\title{
Advancing Social Change by Synergizing Nonprofit Organizations with Common Missions
}

\author{
Syed Aftab Hayat \\ Project Team: Syed Aftab Hayat, Nick Colicchio and David Laux \\ Correspondence: Syed Aftab Hayat, School of Business, Maryville University, St. Louis, MO, USA.
}

Received: February 19, 2014

Accepted: March 7, $2014 \quad$ Available online: June 2, 2014

doi:10.11114/ijsss.v2i3.350

URL: http://dx.doi.org/10.11114/ijsss.v2i3.350

\begin{abstract}
The aim of this study is to advance the efforts of nonprofit organizations in achieving their missions. In the form of a case study, the paper discusses how this can be achieved by bringing together the resources of different nonprofit and for profit organizations that serve a common cause/mission. An endeavor is made for helping an eye care charity organization by impacting it in both a positive and sustainable manner. The effort reaches to various organizations related to eye healthcare in order to seek out the common cause they all are working for. It is found out that the more closely related the missions of the organizations are the stronger and more effective will be the resultant synergies of their collaboration. Although the work of this study is preliminary however it serves as a good model for any nonprofit to reap benefit from and significantly enhance its effectiveness towards reaching its goals. The research hopes that it can fundamentally advance and impact how social work is being done on a global platform.
\end{abstract}

Keywords: improving social work, synergizing nonprofits, common missions of nonprofit, not-for-profit collaboration, advancing social welfare, enhancing nonprofit effectiveness

\section{Background and Motivation}

The study is being undertaken as part of a social change project initiated during an ethics course in the graduate studies of the team. The aim is to bring about a positive social change for a nonprofit organization. An important characteristic of this change is that it should have an impact and be sustainable so as to benefit it beyond the duration of this project.

It is pertinent to mention that the success of any project is based upon the commitment and motivation of its team. One must stop and think about giving back to the community whose resources like roads, hospitals and education we use everyday for our personal needs. The opportunity provided by this project was a source behind the motivation and ethical intent of the group members who tried to reach out by helping a nonprofit working for the community.

\section{Related Work}

Several collaborations techniques were reviewed to find ways to impact an organization. To have a high impact, all sectors of a society must be mobilized - government, businesses, nonprofits, and public (Grant, Crutchfield, 2007). Collaboration can be attained through varied models using cyber strategies (Brainard, Siplon, 2004), overhead minimization (Mitchell 2013), operational reviews (Reider, 2001), improving grant seeking (Zweibel, Golden, 2007), dismantling barriers between organizations (Nambisan, 2009) or capping fostering public-private partnerships (Grubbs, 2000).

Successful examples of partnerships among nonprofits serving the society include providing homes for the homeless using networking (Wei-Skillem, Marciano, 2008), child care and education using interagency variations (Sally, Sowa, Sandfort, 2006), prevention of child maltreatment using administrative and frontline operations (Elizabeth, 1997), religion using people of different faiths (Rogers, 2009). Concepts from outside the nonprofit realm have used multi agent systems (Wooldridge, 2009) to improve collaboration in foraging (Hayat, Niazi, 2005) and situation management (Kovalenko, Velev, 2012).

InnoCentive is mentioned by (Nambisan, 2009) as an innovation intermediary that brokers relationships between those with questions and those with answers. Nambisan further illustrates an example of how InnoCentive reaches out to 160,000 individuals worldwide to solve a question for a foundation which it could not have solved on its own. This case demonstrates the power of collaboration and its significance in improving the effectiveness of organizations. The virtually untapped potential of networks in the philanthropic sector paints a hopeful picture of what the sector has the power to achieve (Wei-Skillem, Silver, 2013). This paper uses some of the concepts from these techniques and proposes 
a novel way to rapidly impact a nonprofit.

\section{Introduction}

\subsection{Selecting and Formulating a Strategy for the Collaborating Partner}

The first thing requiring collaboration is to identify a target peer to seek help from. These peers can be classified into two broad groups.

1) For-Profit organizations

2) Nonprofit organizations (including government and foundations)

\subsubsection{For-Profit Organizations}

The goal of the for-profit organizations in general is to maximize shareholder value of the investors and be at least profitable. Two ways were found most effective in seeking help from such organizations a) using their mission statement b) using their community service obligations.

Every organization whether profit or nonprofit has a mission statement. The mission statement rises above the profitability goal of the organization and generally addresses a need in the industry or forming a positioning strategy within its industry. Management of for-profit companies should be more willing to help if an entity seeking their help can outline to them how it is related to the mission of the company? Once a nonprofit can make the management of for-profit company understand that their contribution of helping the nonprofit is a part of the company's mission statement then it gets much easier to draw them to help.

Similarly many companies are required to give back to their communities under state and county regulations. They earn credits and good will which may help them in expansion and projecting a good image for the company. It is only natural for a company to first help its local community or target clientele before reaching out to other sector of the societies.

The human resource at the for-profit company is primarily engaged in making value for the company and hence these companies find it easy to help others through financial means. Although such relationships are difficult to foster but once established, they can have significant financial impact.

Even if not under any obligations many companies are becoming more socially aware and include community service programs as part of their operations. Hence it is very easy to reach to companies that are working in a related domain or with similar missions.

\subsubsection{Nonprofit Organizations}

These organizations are mostly running on funds and grants and have limited financial resources. The nonprofit status of the organization represents its dedication in achieving its mission/cause. It has already defined its mission to carry out the requisite objectives and doesn't need anything in return to help someone falling within its domain. The existence of most nonprofits is based on the concept of helping somebody. Although the application area in which these organizations work is sometimes very narrow but nonprofits work for a greater cause and are very motivated to help.

Approaching through the 'common mission statement' technique discussed in the previous section can be used to seek help from such organizations as well. Most nonprofits will only have the service or item it is working for to offer to others, hence relationship with such organizations can be made fruitful based on the concept of 'barter'. That is to identify nonprofits that can mutually benefit from the services or products and both have something they can give to each other.

\section{Methodology}

The selection of the nonprofit for the choice of this case study played an important role in the success of the social change project. Selection was based on two main criterions:

1) There should either be a prevailing need at the nonprofit that the group should address or propose suggestions to the nonprofit that should positively impact it

2) The task goals should be kept realistic. Focus of need identification for the nonprofit was kept on improving areas for which the team could add value through its skills, knowledge or technical abilities rather relying on capital and financial means.

Organizations were reviewed by searching through online and published directories and listings. The organizations were contacted through phone calls and emails. After getting in touch with various nonprofits, the group finally came across Eye Care Charity of Mid America (ECCOMA). Upon learning that ECCOMA had four Core Assistance Programs that touched domestic and international people in need, the utilitarianism approach (Dennis, 2012) was adopted in which the group believed that helping this particular non for profit would benefit the greatest number of people and in theory knew that this was the best decision in lieu of available options. This formed the basis of the ethical and social motivation behind the selection criterion. Also, from the preliminary meetings with the stakeholders at ECCOMA, the team figured out that they just might have the requisite skill sets to be able to fulfill the needs for this particular 
organization and selected ECCOMA fort this social change.

Other organizations that were narrowed down but a match could not be made during the search process were dealing with physiological care and Sudden Infant Death Syndrome (Hogberg \& Bergstorm, 2000).

\subsection{Understanding the Nonprofit and Its Mission}

It is important to develop an understanding of the work the nonprofit is doing before identifying potential improvement areas. An excerpt from the mission statement of ECCOMA sets a good outline of its work "Eye Care Charity of Mid-America is dedicated to enhancing quality of life by providing vision improvement and access to a bright future in our society". They thrive to accomplish their mission on a local and international level. They are dedicated to improve access to vision care through eye care services and eye health education through Core Assistance Programs such as the Care-mobile, World Missions, Pro-bono Surgeries and local Clinics.

The largest program they offered was the "Care-Mobile" (Munz, 2013), whose focus area is the 14 counties throughout the metro St Louis region. The Care Mobile is a fully equipped optometric office which includes an optical lab where workers can produce eyeglasses on-the spot. ECCOMA serves approximately 20 children per day and over 2100 annually ("Vision Program", 2014). Each child receives a comprehensive eye exam and if needed a new pair of eyeglasses with case and eye health education. Another powerful assistance they offer is Pro-bono surgeries. These surgeries include Lasik and retinal detachment.

Having established an understanding the work of ECCOMA, requirements were gathered by conducting meetings with the stakeholders and employees at ECCOMA and listening to their problems. Potential improvement areas were found using gap analysis (Mikoluk, 2013).

The plan included decreasing expenses, enhancing effectiveness and increasing exposure by identifying and forming strategic partnerships with all those willing to help ECCOMA and its mission. This resulted in several successful accomplishments which we discuss in the next section.

\section{Impacting the Nonprofit Sustainably}

\subsection{Improving Material Sourcing}

Need: ECCOMA identified the need of not having eye glass wipe cloths to give to children with a new pair of subscription glasses.

Effort: Local eye care goods distributors were approached along with creative design studios (logo design companies) who were involved in doing custom printing of company logos on varying products. These logo design companies would be able to print the logo of ECCOMA on the wipe cloths as well.

Impact: The effort resulted in over $\$ 1,000$ of donated products of wipe cloths from Amcon Labs-an eye care supply center in St. Louis. ECCOMA now has better access to material and service which will ultimately help them financially and their patients/clients physically.

Sustainability: A relationship has been developed between the organizations. They can now build upon it and improve it in future as well.

\subsection{Decreasing Maintenance Costs of Care Mobile}

Need: The Care-Mobile had no existing maintenance being carried out. As ECCOMA had mostly volunteers working for it, the current person incharge of the vehicle could only put enough hours to cover the driving requirements of the Care-Mobile was not prepared to take on the additional job of fully maintaining the vehicle.

Effort: The vehicle was recently purchased and currently did not have much maintenance requirement. The project team realizing that maintenance will be a cause of concern in the future as the vehicle got older, looked for a sustainable ways to provision for this need.

Impact: A partnership with a local truck center was established. The local truck center was willing to help ECCOMA as part of its welfare contribution. The collaboration resulted in prevailing a bi-annual maintenance on the Care-Mobile at no cost. Measuring the old expenditure it was estimated that this effort would equate to roughly $\$ 600$ in savings per year

Sustainability: This service has no time duration and can be enjoyed by ECCOMA in the coming years as well.

\subsection{Developing Strategic Partnership for Pro-Bono Surgeries}

Need: During the Care-Mobile events when eye exams would take place at different schools, children are seen by volunteering optometrists on board the Care-Mobile who perform an eye exam before they are prescribed or given any eye glasses. In some of these cases, the children might be suffering from different eye diseases which are causing the eye sight deficiency which cannot be remedied through prescription eye glasses alone. These children might need to be 
referred to ophthalmologists for advanced diagnostics or surgeries.

Effort: Following clinics and associations were reached out to help ECCOMA in providing pro-bono surgeries for patients that required additional care.

Volunteers in Medicine (VIM), St. Louis. A nonprofit health clinic approached through Mr. Abdul Wadood

Peppose Eye Vision Institute, St. Louis. An eye clinic approached through Dr. Mujtaba Qazi

Wildwood Vision Specialists (WVS), St. Louis. An eye clinic approached through Dr. Christy Hayes

\section{Impact:}

VIM: VIM provides for healthcare primarily to the uninsured between the ages of 18 and 60 who are not generally covered by schemes under the US federal government like Medicaid and Medicare. On the other hand ECCOMA although doesn't deny eye glasses to anybody coming to them but generally caters for children under the age of 18 years old. Due to this stark difference in the target patient profiles that both addressed, no immediate arrangement could be developed that would be mutually beneficial to both the companies.

Peppose Eye Vision Institute: ECCOMA would provide potential nurse candidate through the resume database that it maintained. It will also send surgery candidates that it comes across to Peppose who can look at those patients during the time set aside for pro-bono surgeries. Peppose through its affiliates will provide help with clinical opportunities for medical students and volunteering optometrists during care-mobile events. ECCOMA will look into catering requests of mobile eye clinics in schools identified by Peppose.

WVS: Eye doctors here were committed to providing social-welfare to the community and look forward to helping patients being referred by ECCOMA who required advanced eye care.

Sustainability: Through meetings and communications facilitated by the project team, important point of contacts were established between the organizations and ECCOMA. Although nothing substantial could be achieved with VIM but all the organizations were very excited over the preliminary meetings and hoped to look into ways of developing long term relationships in the future.

\subsection{Increasing Social Media Presence (Print and Electronic)}

Need: The welfare work of ECCOMA needed to be spread out and projected so that it could gain critical media exposure needed to develop a good image and spread the cause to those who needed it in the community.

Effort: The team gained key exposure for ECCOMA in the Optometrist community by placing ECCOMA in the St Louis Optometrist Society (SLOS) newsletter. Generic templates were developed to serve the current requirements of the newsletter, they can also be improved to incorporate future changes as well. Creation of a LinkedIn account and placement on the Wildwood Vision website will add to the media reach of ECCOMA. Furthermore, talks were initiated with a potential resource for spreading ECCOMA's mission to KSDK (a local news channel) for potential focus in upcoming months. Volunteer appreciation certificates templates were also developed individually by the group as well.

Impact: The enhanced media exposure will continue to prevail with ECCOMA having a space in each issue of St. Louis Optometrist Society newsletter. This will also increase ECCOMA outreach to potential donors as all nonprofits can benefit from external funding and donations.

Sustainability: Extended media outreach will give access to new avenues the organization did not have access to before. The effort of developing generic template and certificates, acknowledges volunteers, which will be a continuous source of motivation and inspiration.

\subsection{Conducting a Green Study for the Care-Mobile}

Need: The Care-Mobile currently uses diesel for its fuel but has the provision to run on bio-diesel. It was decided to conduct a 'going green' study by doing a cost-benefit analysis for using bio-diesel fuel.

Effort: Rates were taken of different types of bio-diesel provided by MFO Oil, a company dealing in bio-diesel fuel for St. Louis market. Cost comparisons along with direct bio-diesel delivery options were reviewed.

Impact: It was found that bio-diesel fuel becomes very viscous in winters owing to its properties and requires increases maintenance on the vehicle. Along with that the cost of shifting to bio-diesel fuel was slightly higher than conventional fuel. It was also found out that for the amount of consumption, delivery of bio-diesel fuel to the location of the truck was not feasible.

Sustainability: It was not recommended to shift the Care-Mobile bio-diesel. The green initiative would only be sustainable if it found an adequate sponsor in the form of a supply company that could benefit from providing sales to a nonprofit and could somehow translate that into a financial benefit by subsidizing the cost of bio-diesel fuel supplied to ECCOMA. 


\subsection{Improvement in Information Technology (IT) Architecture}

Need: The Care-Mobile had the patient database and the software required to access the records. Each time patient information was required, someone from the ECCOMA staff would have to physically go the van and look up the information there.

Effort: IT architecture was improved by suggesting fixes to the Local Area Network (LAN) ports on board the truck. Also diagnostics were performed on the software to see the best method of accessing it and it was found out that connecting the Care-Mobile with a wireless internet connection would be the best option. This will enable them to access information remotely without physically going to the van. During the project informational accuracy of ECCOMA website was enhanced by pointing out key flaws such as typographical errors and grammar mistakes.

Impact: This resulted in reduced load on staffing and increased office productivity. The effort would further enable optometrists on board the Care-Mobile to be able to play online instructional and eye exercise videos for the patients as well.

Sustainability: The improvements were made to the architecture and will last beyond the duration of the project time.

\subsection{Other Efforts and Limitations}

Other efforts included assistance in providing grant information from Laclede Gas Company the local gas supply company for ECCOMA.

Some attempts were not successful as well. Due to lack of time reaching out to the school board at University of Missouri St. Louis (UMSL) for providing optometrists could not be fully pursued. Volunteering optometrists to help on board the Care-Mobile during its operational days visiting and making eye glasses was a key need of ECCOMA which went unmet. Providing help in this matter remains a key area for future work with ECCOMA.

\section{Conclusion}

Analyzing the results of this study for the nonprofit, it was found that, more closely the related the missions of the organizations are, stronger will be the collaboration between them. This can further supplement towards development of effective and sustainable relationships between them. Great benefits can be reaped through aligning and bringing together both non-for-profit and for profit organizations in order to serve the community by adhering more closely towards their respective missions.

The exercise proved beneficial in mainly achieving three things for ECCOMA- decreased expenses, increased exposure and enhanced effectiveness. This was demonstrated successfully by formation of key strategic partnerships along with individual efforts towards reaching out to organizations with the methodology of common missions proposed in this paper. The short duration of this project suggests that this model can be used to improve a nonprofit's effectiveness when rapid results are required. This might by suitable in war like or hostile environments where time might be a constraint due to safety or other reasons. This study serves as a platform for much greater synergies to be accomplished by advancing social welfare initiatives at a global level.

\section{A Personal Note from the Project Team}

There is always an unmet need. For a child undergoing eye treatment, there is still the need to get a pair of eye glasses (Diana, 2008). As a child or young adult who is generally in good health, it is far too easy to take the gift of sight for granted. At one point in our lives we have all be exposed to an individual in desperate need for help. During these times, we may have good intentions in our hearts as well as empathy for those before us. But more often than not, we pass up the opportunity to help and move on with our daily lives with little to no regret.

ECCOMA had their hands full in trying to help everyone. Unfortunately, they lacked the resources to really be firing on all pistons, which, also provided an opportunity to help us identify its need areas. The thought kept su us motivated and transformed the individuals of the team into a functioning group. We were met with different obstacles throughout this project, our largest being time. After our initial meeting, we divided our ideas amongst the group based upon our individual knowledge and expertise. It did not take long for disappointment to set in when all of our ideas fell flat and it seemed like we were not making any progress.

Despite our struggles and challenges, everything started to come together near the end. During the past several weeks we have been given the opportunity to give back to the community. The pride we have felt as a group and individuals during this endeavor has far exceeded any of our expectations. The amazing drive to help others became intoxicating and made us want to become better people.

\section{Acknowledgement}

With the grace of God, the author would like to thank his father and mother and beloved family for their continuous support and motivation. The project team found some great friends amongst them while working for this cause. 


\section{References}

Brainard, L. A., \& Siplon, P. D. (2004). Toward nonprofit organization reform in the voluntary spirit: Lessons from the internet. Nonprofit and Voluntary Sector Quarterly, 33(3), 435-457. http://dx.doi.org/10.1177/0899764004266021

Dennis, C. (2012). Business Ethics: How to Design and Manage Ethical Organizations, Wiley.

Diana, A. (2008). We had laser eye surgery but still need our specs. The reality of the permanent sight cure. http://www.dailymail.co.uk/health/article-1051575/We-laser-eye-surgery-need-specs--The-reality-permanent-sightcure.html (accessed on 20 Jan, 2014)

Elizabeth, A., \& Mulroy, S. S. (1997). Nonprofit organizations and innovations: A model of neighborhood-based collaboration to prevent child maltreatment. Social Work, 42(5), 515-24. http://dx.doi.org/10.1093/sw/42.5.515

Grant, H. M., \& Crutchfield, L. R. (2007, Fall). CREATING HIGH-IMPACT NONPROFITS. Stanford Social Innovation Review, 5, 32-41

Grubbs, J. W. (2000). Can agencies work together? collaboration in public and nonprofit organizations. Public Administration Review, 60(3), 275-280. http://dx.doi.org/10.1111/0033-3352.00087

Hayat, S. A. \& Niazi, M. (2005), Multi-agent foraging - taking a step further Q-learning with search. Proceedings of IEEE international conference on emerging technologies. (ICET05) pp. 215-220, September 2005, Islamabad, Pakistan.

Hogberg, U., \& Bergstrom, E. (2000). Suffocated prone: The iatrogenic tragedy of SIDS. American Journal of Public Health, 90(4), 527-31. http://dx.doi.org/10.2105/AJPH.90.4.527

Kovalenko, Oleksiy E., Velev, \& Dimiter G. (2012). Integration of Information Services in Agent-Oriented Situation Management System. International Conference on Applicatoin of Information and Communication Techonology and Statistics in Economoy and Education (ICAICTSEE-2012) pp 132, October 5-6 $6^{\text {th }} 2012$, UNWE, Sofia, Bulgaria.

Mikoluk, K. (2013). Gap Analysis Template: The 3 Key Elements of Effective Gap Analysis. https://www.udemy.com/blog/gap-analysis-template/ (accessed on 25 Jul, 2013)

Mitchell, G. E. (2013). The construct of organizational effectiveness: Perspectives from leaders of international nonprofits in the united states. Nonprofit and Voluntary Sector Quarterly, 42(2), 324. http://dx.doi.org/10.1177/0899764011434589

Munz, M. (2013). Students grateful for eyeglasses from area's first mobile vision clinic. http://www.stltoday.com/lifestyles/health-med-fit/health/health-matters/students-grateful-for-eyeglasses-from-areas-first-mobile-vision/article_3ed49aba-eb9e-5bdf-82d3-f0000353abf5.html (accessed on 5 Mar, 2014)

Nambisan, S. (2009, Summer). Platforms for collaboration. Stanford Social Innovation Review, 7, 44-49.

Reider, R (2001). Improving the economy, efficiency, and effectiveness of not-for profits; conducting operational reviews. Reference and Research Book News, 16(3) Retrieved from http://search.proquest.com/docview/199580250?accountid=40561

Rogers, R. K. (2009). Community collaboration: Practices of effective collaboration as reported by three urban faith-based social service programs. Social Work and Christianity, 36(3), 326-345

Sally, C. S., Sowa, J. E., \& Sandfort, J. (2006). The impact of nonprofit collaboration in early child care and education on management and program outcomes. Public Administration Review, 66(3), 412. http://dx.doi.org/10.1111/j.1540-6210.2006.00598.x

Stripling, B. (2003). Working across boundaries: Making collaboration work in government and nonprofit organizations. PM.Public Management, 85(6), 28.

Vision Program-Eye Care Charity of Mid America (ECCOMA). http://eccoma.org/eccoma-vision-programs/(accessed on 5 Mar, 2014)

Wei-Skillern, J., \& Marciano, S. (2008, Spring). The NETWORKED NONPROFIT. Stanford Social Innovation Review, $6,38-43$

Wei-Skillern, J., \& Silver, N., PhD. (2013). Four network principles for collaboration success. The Foundation Review, 5(1), 121-129, 12. http://dx.doi.org/10.4087/FOUNDATIONREVIEW-D-12-00018.1

Wooldridge, M. (2009). An Introduction to Multi Agent Systems. ISBN-13: 978-0470519462.

Zweibel, N. R., \& Golden, R. L. (2007). What foundations and nonprofits can do to foster productive relationships. Generations, 31(2), 41-46. Retrieved from http://search.proquest.com/docview/212229477?accountid=40561

\section{(cc) $\mathrm{EY}$}

This work is licensed under a Creative Commons Attribution 3.0 License. 